\title{
Aspects Regarding of a UGV Fire Fighting Thermal Shield ${ }^{\dagger}$
}

\author{
Lucian Ștefăniță Grigore ${ }^{1} \mathbb{D}$, Amado Ștefan ${ }^{1}$, Ionica Oncioiu ${ }^{2, *} \mathbb{1}$, Cristian Molder ${ }^{1} \mathbb{D}$, Damian Gorgoteanu ${ }^{1}$, \\ Daniel Constantin ${ }^{1}$ and Răzvan-Ionuț Bălașa ${ }^{1}$
}

1 Military Technical Academy “FERDINAND I", 39-49 George Coșbuc Av., 050141 Bucharest, Romania; lucian.grigore64@gmail.com (L.S.G.); amado.stefan@mta.ro (A.S..); cristian.molder@mta.ro (C.M.); damian.gorgoteanu@mta.ro (D.G.); daniel.constantin@mta.ro (D.C.); balasa.razvan@rocketmail.com (R.-I.B.)

2 Faculty of Finance-Banking, Accountancy and Business Administration, Titu Maiorescu University, 040051 Bucharest, Romania

* Correspondence: ionica.oncioiu@prof.utm.ro; Tel.: +40-372-710-962

+ Presented at the 8th International Symposium on Sensor Science, 17-28 May 2021; Available online: https://i3s2021dresden.sciforum.net/.

Citation: Grigore, L.Ș.; Ștefan, A.; Oncioiu, I.; Molder, C.; Gorgoteanu, D.; Constantin, D.; Bălașa, R.-I. Aspects Regarding of a UGV Fire Fighting Thermal Shield. Eng. Proc. 2021, 6, 83. https://doi.org/ 10.3390/I3S2021Dresden-10082

Academic Editors: Gianaurelio Cuniberti and Larysa Baraban

Published: 17 May 2021

Publisher's Note: MDPI stays neutral with regard to jurisdictional claims in published maps and institutional affiliations.

Copyright: (c) 2021 by the authors. Licensee MDPI, Basel, Switzerland. This article is an open access article distributed under the terms and conditions of the Creative Commons Attribution (CC BY) license (https:/ / creativecommons.org/licenses/by/ $4.0 /)$.

\begin{abstract}
This article presents aspects related to the protection (with a double shield made of stainless steel) of a robot for emergency situations against the effect of flames due to a fire. The ground robot is semi-autonomous/autonomous, with a wheeled propeller $(6 \times 6)$. The robot, designed and built at the TRL 2 level, is intended for fire investigation, monitoring, and intervention (and, in particular, for petrochemical plants). The role of the shield is to protect the equipment that is part of the robot including its controllers, sensors, communications, power supply, etc. The need to mount a thermal protection shield on the intervention robot was given by the fact that fires at petrochemical plants generate very large thermal fields and gradients which are responsible for creating blind spots. These blind spots do not allow intervention crews to see what is happening in that area. These blind spots are characterized by very high temperatures. The dynamics of these fires can be unpredictable. Therefore, to analyze the performance of the heat shield in this study we perform a numerical-experimental analysis.
\end{abstract}

Keywords: robot; thermal; shield; sensors; firefighting; emergency

\section{Introduction}

Using robotic systems for risk situations intervention is extremely useful [1-3], and using them on a large scale helps to protect endangered personnel and increase the efficiency with which intervention missions are performed [4-6]. However, it is recommended that robotic intervention systems are equipped with radiation protection equipment [7-10] and equipment to protect against the high temperatures generated by fires [11-14], since it is possible that the moving path of the fire intervention robot might pass through areas which are contaminated with radiation, chemical substances, etc. Excessively equipping the robot with sensors isn't the best solution. This is why additional risk area monitoring systems are used for areas where robotic system must intervene [15-21].

Designing complex and robust robotic intervention systems has led to prohibitive prices. In this sense, it is necessary to take into consideration low-cost solutions so that an efficiency from the material point of view can be maintained [22-24].

The method of declaring the issue involves the following question: which is the optimal solution so that intervention robots are operational while simultaneously ensuring a degree of protection against external destructive actions?

By virtue of the antagonism of the two requirements (i.e., optimal intervention [25-28] versus protecting the robot [29-31]), it has been considered that the task, in a manner which ensures feasible compromises, can be reduced to the following: identifying conditions imposed by the types of propulsion (e.g., on wheels or on tracks); identifying the payload [32-36]; identifying the dynamical characteristics depending on the terrain and 
artificial obstacles [37-43]; determining limitations due to the low level of predictability of the evolution of the fire [44-47]; determining limitations due to the level of thermal gradients of the heat sources [48-53]; and identifying the material characteristics specific to the structure of the robot and to the components destined to the protection of the robot and the equipment (sensors, batteries, controllers, etc.) against high temperatures [54-56].

From our research point of view, the task involves to the possibility of robot design imperfections occurrence, since it will be TRL2, in the research laboratory; the lack of specialized utilities at the level of the laboratory for mechanical processing of high temperatures resistant; establishing the geometrical shape of the protection system so that, from the thermodynamic point of view, refraction and reflexion coefficients corresponding to reducing the thermal energy of the robot can be obtained [57-60]; establishing a numerical-analytical model for calculating the thermal transfer processes

The actual state of the research domain represented in the specialized literature [61-66], and testing and evaluating the protection system against high temperatures; allows us to analyze an important part of the robot fire intervention.

From studying the specialty references [61-66], the various requirements of the beneficiaries, and the diverse requests of the beneficiaries, of the requirements imposed by the DOR (Documents with Operational Requirements), MND (Mission Needs Documents) operational environment, the following requirements specific for a fire intervention robot have been generated: it should be accessible from the costs point of view; it should operate both from inside and from outside; it should acquire data from the environment; it should be able to communicate from distances as big as possible; it should not be influenced by gamma radiation; it should be able to operate in both a remote control and an autonomous regimen; it should transmit large data quantities; and it should evaluate and map the interior of the buildings so that the data is transited to an operator and the intervention team can know which are the dangers.

The purpose of this article is to analyze and validate a numerical-analytical model for the behaviour of an item thermal protection equipment, namely a thermal shield (Figure 1).

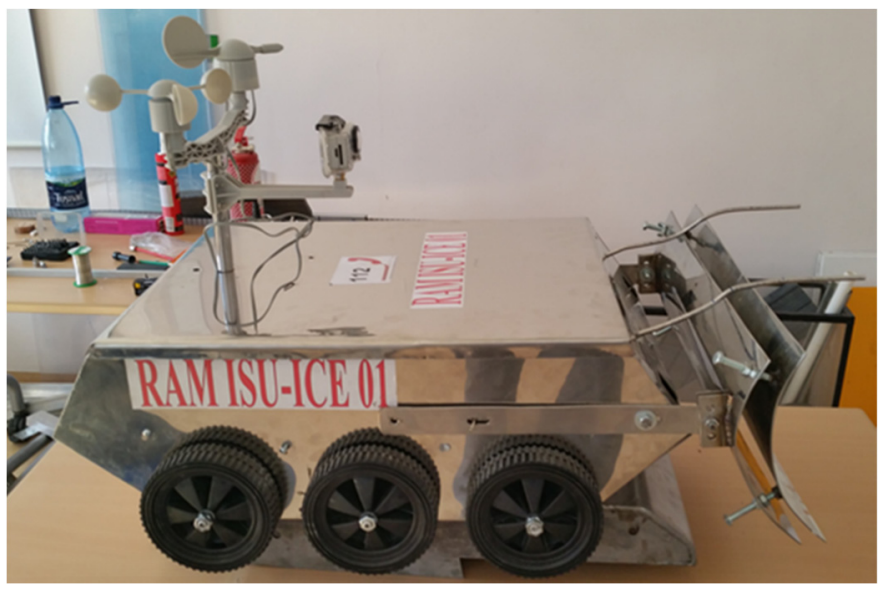

Figure 1. Fire fighter robot equipped with a thermal protection shield.

\section{The Thermal Shield}

\subsection{Materials Used}

The preliminary characteristic situations for choosing a suitable material for the thermal shield are that the robot is stationary; the environment temperature is $+20^{\circ} \mathrm{C}$; the atmospherically humidity is $60 \%$; the atmospheric pressure is $1015 \mathrm{mbar}$; and the wind velocity is $0.5 \mathrm{~m} / \mathrm{s}$ (Figure 2 ). 


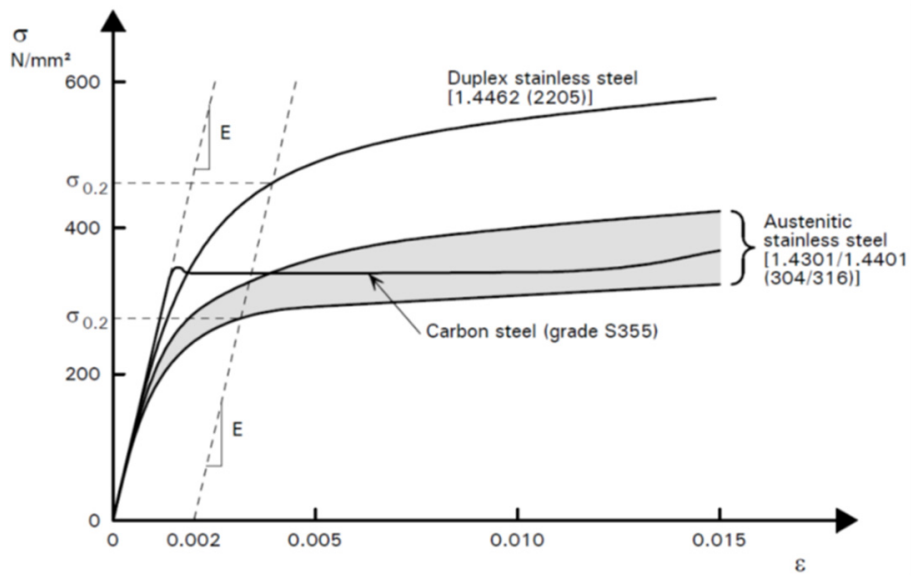

Figure 2. Representing the stress curves for stainless steel and carbon steel, P291: Structural design of stainless steel, Published by: The Steel Construction Institute Silwood Park Ascot Berkshire SL5 7QN. The stainless steel is polished, leading to an emissivity index of 0.16 to an environment temperature of $+20^{\circ} \mathrm{C}$.

The design guide for the material which has been used (stainless steel) follows the BS 5950-1 international standards, the good practice code, published by BSI in 2000, the Eurocode stainless steel ENV 1993-1-4 recommendations, and from other sources, with adequate changes made in order to implement the recommendation in the BS 5950-1:200 format.

The main characteristics are represented by the high capacity of thermal impact absorption due to the excellent ductility (especially for the austenite classes).

\subsection{Geometrical Characteristics}

In the case of our study, we have equipped a robot for intervention in emergency situations (fires) with a thermal shield. The purpose is to reduce the total heat transfer between two radiant surfaces.

This thing can be achieved by placing a system of two shields against radiation between surfaces (i.e., emitter and receiver) [67]. The heat transfer through this layered construction is dominated by radiations (Figure 3 ).

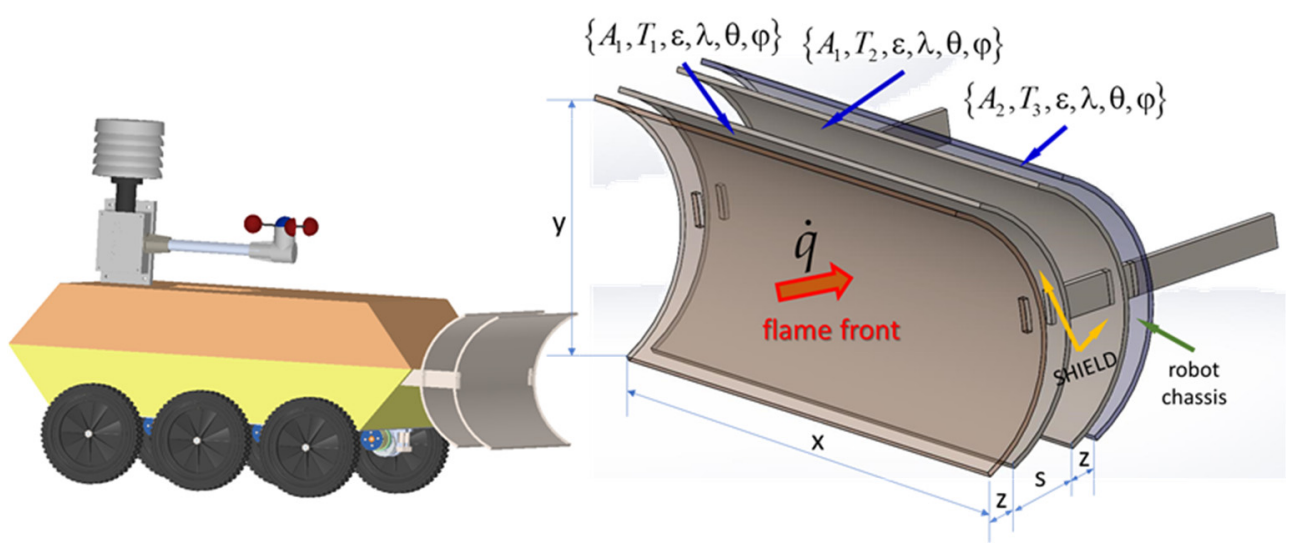

Figure 3. Radiation Shield between two parallel planes.

The thermal transfer is produced through finite surfaces (the thermal shields), which have reduced emissivity indices (the Law of Kirchhoff-rel. 3).

Thus, the surface of the shield against radiation will be highly reflective, reducing the net radiative heat transfer through the two shield surfaces when the two of them are 
placed together in series. In the infinite case, the emissivity factor between the two surfaces is equal to the unit since the surfaces were considered dimensionally infinite.

Since this thing cannot happen [68] (3.107), thus relationship (1) becomes:

$$
\dot{q}_{14}=\frac{\sigma\left(T_{1}^{4}-T_{2}^{4}\right)}{\left(\frac{1-\varepsilon_{1}}{\varepsilon_{1} A_{1}}+\frac{1}{A_{1} F_{1-2}}+\frac{1-\varepsilon_{2 A}}{\varepsilon_{2 A} A_{2}}+\frac{1-\varepsilon_{2 B}}{\varepsilon_{2 B} A_{2}}+\frac{1}{A_{3} F_{2-3}}+\frac{1-\varepsilon_{3 B}}{\varepsilon_{2 A} A_{3}}+\frac{1-\varepsilon_{3 B}}{\varepsilon_{3 B}}+\frac{1}{A_{3} F_{3-4}}+\frac{1-\varepsilon_{4}}{\varepsilon_{4} A_{4}}\right)}\left[\mathrm{W} / \mathrm{m}^{2}\right]
$$

\section{The Analytical Model}

\subsection{The Thermodynamic Laws}

The thermodynamic laws which ensure the support for the analytical model are as follows: Prevost's law; Kirchhoff's Laws; the Stefan-Boltzmann law; Plank's Law; Wien's Laws; the Reyleigh-Jeans law; and Lambert's law. Taking the previous laws into consideration, we obtain the total power of emission includes the radiant energy of all of the significant wavelengths for the thermal radiation and can be determined in the following manner:

$$
E_{T}=\int_{0}^{\infty} \varepsilon_{\lambda} E_{\lambda} d \lambda=\varepsilon_{T} E_{0 T}=\varepsilon_{T} \sigma T^{4}
$$

\subsection{Analytical Method for Determining the Temperature Variation in the Thermal Shield}

The analytical method for determining the temperature variation in the material is as follows:

$$
\Delta \theta_{S}=\frac{\alpha_{c}+\alpha_{r}}{c_{S} \cdot \rho_{S}} \cdot \frac{H_{p}}{A_{g}} \cdot\left(\theta_{f}-\theta_{S}\right) \cdot \Delta t
$$

where: $c_{S}[J / \mathrm{kgK}]$ is the specific heat for the stainless steel; $\rho_{S}\left[\mathrm{~kg} / \mathrm{m}^{3}\right]$ is the stainless steel density; $\theta_{f}\left[{ }^{\circ} \mathrm{C}\right]$ is the flame temperature at a given moment $t[\mathrm{~s}] ; \theta_{S}\left[{ }^{\circ} \mathrm{C}\right]$ is the temperature of the stainless steel section, considered uniform, at the same given moment $t[s] ; \frac{H_{p}}{A_{g}}\left[m^{-1}\right]$ is the coefficient of the section, the ratio between the heated perimeter $H_{p}[m]$ to the gross transversal area $A_{g}\left[m^{2}\right]$; and $\alpha_{c, r}\left[\frac{W}{m^{2} K}\right]$ is the convection heat transfer coefficient.

The designed shield is a system made from two relatively thin semi-round plates, opaquely placed in the direction perpendicular on the radiated heat propagation. As it has been previously mentioned, it is made from materials with low absorption and high reflectivity. In this case, two sheets made from stainless material have been used for the manufacturing of the shield. We mention that the chassis of the robot is made from stainless steel:

(i) With no stainless-steel shields, the net heat exchange between the two parallel infinite planes is:

$$
\left\{\begin{array}{l}
Q_{12}=\left(F_{g}\right)_{12} A_{1} \sigma_{b}\left(T_{1}^{4}-T_{2}^{4}\right)[W] \\
F_{12}=1\left[\left(W / m^{2} K\right)^{-1}\right] \quad A_{1}=A_{2}=A[W / K] \\
\left(F_{g}\right)_{12}=1 / \frac{1}{\varepsilon_{1}}+\frac{1}{\varepsilon_{2}}-1\left[\left(W / m^{2} K\right)^{-1}\right] \\
Q_{12}=A \sigma_{b}\left(T_{1}^{4}-T_{2}^{4}\right) /\left(\frac{1}{\varepsilon_{1}}+\frac{1}{\varepsilon_{2}}-1\right)[W]
\end{array}\right.
$$

(ii) Placing thermal radiation shields does not remove or add heat to the system, but, in equilibrium conditions, the plates of the thermal shields reach the T2 and T3 temperatures, considering that both faces of the shield plates have the same emissivity:

$$
\frac{A \sigma_{b}\left(T_{1}^{4}-T_{3}^{4}\right)}{\left(\frac{1}{\varepsilon_{1}}+\frac{1}{\varepsilon_{3}}-1\right)}=\frac{A \sigma_{b}\left(T_{3}^{4}-T_{2}^{4}\right)}{\left(\frac{1}{\varepsilon_{3}}+\frac{1}{\varepsilon_{2}}-1\right)}
$$


From $(4 \div 5)$ :

$$
\left(Q_{12}\right)_{n e t}=\frac{A \sigma_{b}\left(T_{1}^{4}-T_{2}^{4}\right)}{\left(\frac{1}{\varepsilon_{1}}+\frac{1}{\varepsilon_{3}}-1\right)+\left(\frac{1}{\varepsilon_{3}}+\frac{1}{\varepsilon_{2}}-1\right)}[W]
$$

Computing the ratio between the radiant energy expression with and without shield, we will obtain:

$$
\frac{\text { with shield }}{\text { without shield }}=\frac{\left(\frac{1}{\varepsilon_{1}}+\frac{1}{\varepsilon_{2}}-1\right)}{\left(\frac{1}{\varepsilon_{1}}+\frac{1}{\varepsilon_{3}}-1\right)+\left(\frac{1}{\varepsilon_{3}}+\frac{1}{\varepsilon_{2}}-1\right)}[-]
$$

If $\varepsilon_{1}=\varepsilon_{2}=\varepsilon_{3}$, then the ratio from relationship (22) is $\frac{1}{2}$, which makes it obvious that, by introducing a shield, the heat transfer gets substantially reduced.

If the temperature of the shield plate, the second one from the robot, reaches temperature T3, according to (22), then it will have the value: $T_{3}^{4}=\frac{1}{2}\left(T_{1}^{4}+T_{2}^{4}\right)\left[K^{4}\right]$, case in which the thermal transfer without the shield will be:

$$
Q=\frac{A\left(E_{b_{1}}-E_{b_{2}}\right)}{\left(\frac{1-\varepsilon_{1}}{\varepsilon_{1}}+\frac{1}{F_{12}}+\frac{1-\varepsilon_{2}}{\varepsilon_{2}}\right)}=\frac{A \sigma_{b}\left(T_{1}^{4}-T_{2}^{4}\right)}{\left(\frac{1}{\varepsilon_{1}}-1\right)+1+\left(\frac{1}{\varepsilon_{2}}-1\right)}=\frac{A \sigma_{b}\left(T_{1}^{4}-T_{2}^{4}\right)}{\frac{2}{\varepsilon}-1}
$$

We find that the ratio of the heat flux with a thermal protection shield reduces the thermal flux to half compared to the case in which we could have exposed the robot to thermal radiation without the shield.

Thus, the total resistance of the physical system for $\mathrm{n}$ plates that form a protection shield will be:

$$
R(n-\text { shields })=(2 n+2) \frac{1-\varepsilon}{\varepsilon}+(n+1) \cdot 1=(n+1) \cdot\left(\frac{2}{\varepsilon}-1\right),
$$

so that the heat transfer is expressed thought the following:

$$
Q=\frac{1}{n+1} \cdot \frac{A \sigma_{b}\left(T_{1}^{4}-T_{2}^{4}\right)}{\left(\frac{2}{\varepsilon}-1\right)}
$$

The conclusion which can be reached after the analytical model is that the presence of $n$ component plates for a thermal shield leads to reducing the thermal radiant heat transfer with an $(n+1)$ coefficient $(n+1)$.

\section{Simulating the Behavior of the Thermal Shield through the Finite Element Method}

Let us consider that a flame jet from a burner has been directed towards the shield (Figures 4 and 5).

The general simulation case consists of positioning the burner in the centre of the shield. Furthermore, the three air jet velocities have been taken into consideration: 5, 7.5, and $10 \mathrm{~m} / \mathrm{s}$.

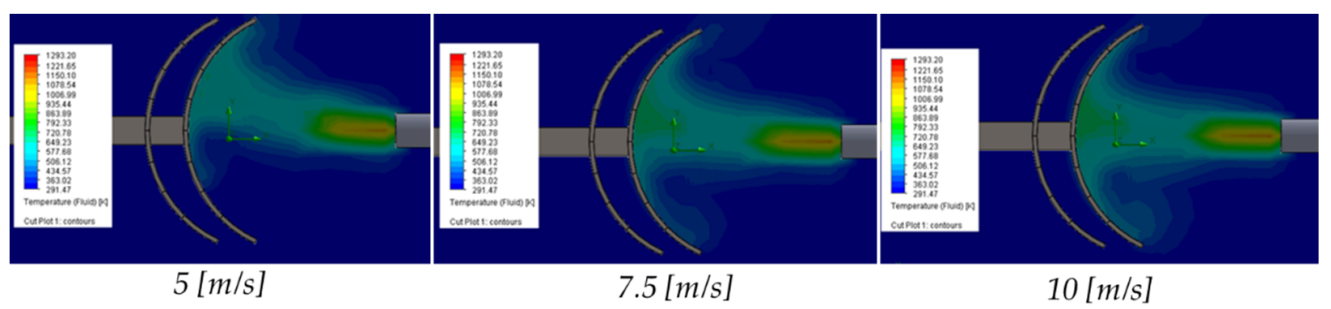

Figure 4. The temperatures of the air jet for the following output velocities $5,7.5$, and $10 \mathrm{~m} / \mathrm{s}$. 


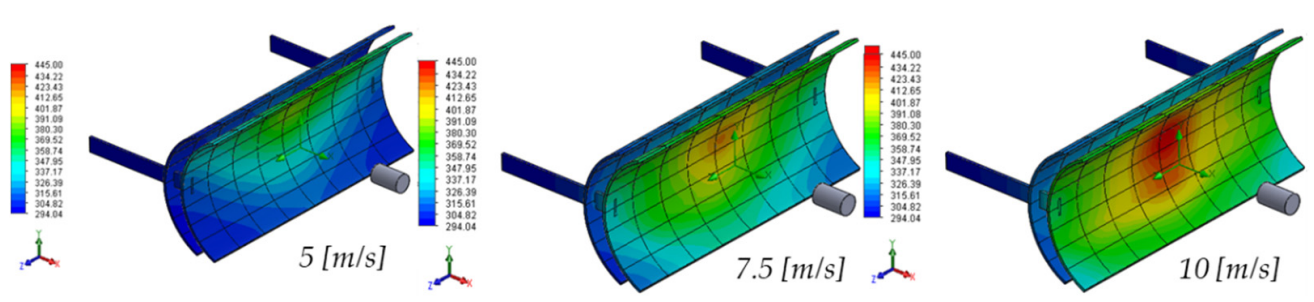

Figure 5. The case of positioning the burner in the center of the shield al of whose air jet velocities are: $5,7.5$, and $10 \mathrm{~m} / \mathrm{s}$.

\section{The Experimental Study Regarding the Behavior of the Thermal Shield under the Action of Fire}

For this experiment we have used a flame obtained from burning liquefied petroleum gas, a hydrocarbons mix composed mainly of propane and butane. The jet flame has been oriented on the longitudinal axis of the shield until the moment when the temperature of the steel became constant. Direct contact with the flame occurred at temperatures over $150{ }^{\circ} \mathrm{C}$. The plate width is $4 \mathrm{~mm}$ (material: Inox 316L), and the exposure time is $4 \mathrm{~min}$. The measurements acquired with the infrared thermometer are represented in the following figure (Figure 6).

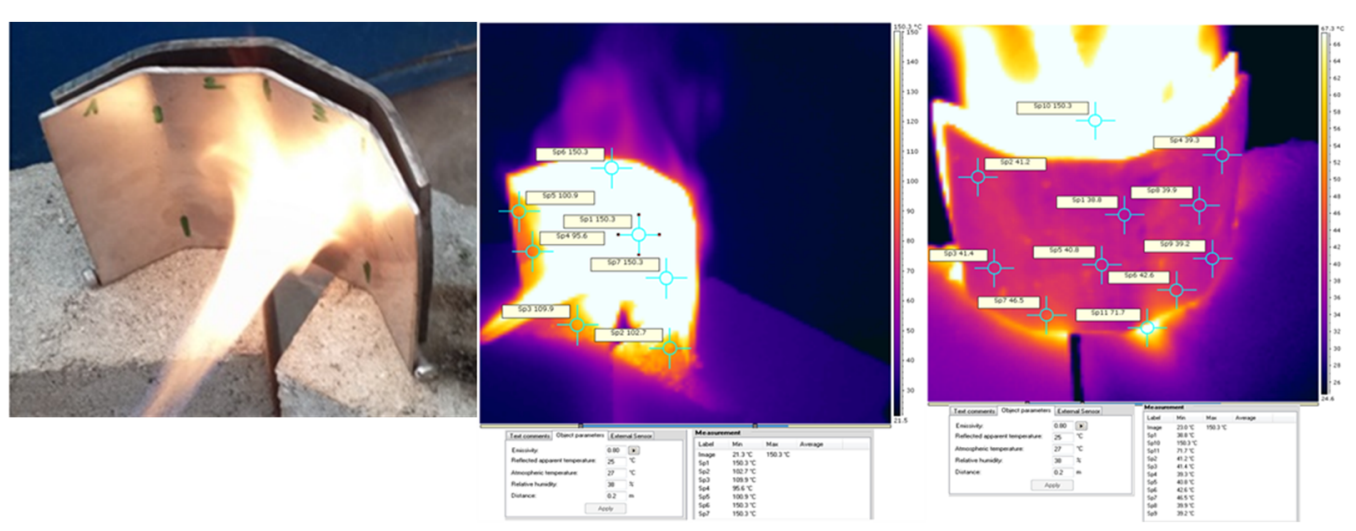

Figure 6. Front and rear-view experimental study with direct contact with the flame at temperatures over $150{ }^{\circ} \mathrm{C}$. The first plate of the shield has a with of $2 \mathrm{~mm}$ and the second plate has a width of $4 \mathrm{~mm}$. The material which has been used is Inox 316L. The testing took $4 \mathrm{~min}$, the flame being directed towards the first concave plate of the shield.

\section{Conclusions}

Although there are substantial uncertainties in the present theoretical and computational models regarding the prediction of thermal shields' evolution for mobile robots, the simulation from chapter four corresponds well to the real conditions:

- The multi-parameter estimation developed for an inverse problem in which we have multiple constant parameters, such as the material properties, are close to the statistical data corresponding to the stainless-steel open flame exposure;

- After the simulation, we could identify the parameters which need to be measured and which should allow recorrelating the numerical analysis calculations with MEF.

- The evolution of the heating phenomenon in time demonstrates that due to the special properties of the stainless steel, the temperature gradients rise moderately;

- Introducing the second wall to the protection shield demonstrates a decrease in temperature on the exposed side;

- In the case of the simulation, upon a nominal analysis the temperature differences can have uncertainties and sensitivity differences, a fact that must be checked during the experiments; 
- In the case of a hot air jet (open flame), as previously mentioned, the problem of an inverse analysis arises in the gas fluid jet modelling (however, this is not the subject of this research);

- Unlike the jet temperature, the surface of the shield gets heated up in time, with different gradients for the same initial simulated (a fact which can be explained due to the molecular structure of the metal from which the shield is made).

\section{Future Developments Directions}

One of the future development directions consists in designing and building a multilayer robot, from the chassis point of view, to reduce its internal temperature.

The second direction of development consistuts in introducing an equipment for detecting dangerous radiation levels in areas which are characterized by high temperatures.

Author Contributions: Conceptualization, L.Ș.G.; methodology, I.O.; software, C.M., D.G. and D.C.; validation, A.S. and L.Ș.G.; formal analysis, D.C., R.-I.B.; investigation, O.A, A.S, and C.M.; writingoriginal draft preparation, I.O. and L.S.G.; writing-review and editing, I.O. All authors have read and agreed to the published version of the manuscript.

Funding: This research received no external funding.

Acknowledgments: This paper has benefited from material support and scientific consulting through the project with the following title "Demonstrator tehnologic-Robot de stins incendii" ("Technological Demonstrator-Fire Extinguishing robot"), with the identification CEXLUM contract number $587 / 09.09 .2014$.

Conflicts of Interest: The authors declare no conflict of interest.

\section{References}

1. Grigore, L.S.; Soloi, A.; Tiron, O.; Răcuciu, C. Fundamentals of Autonomous Robot Classes with a System of Stabilization of the Gripping Mechanism. Adv. Mater. Res. 2013, 646, 164-170. [CrossRef]

2. Nuță, I.; Orban, O.; Grigore, L.Ș. Development and improvement of technology in emergency response. Procedia Econ. Financ. 2015, 32, 603-609. [CrossRef]

3. Peskoe-Yang, L. Paris Firefighters Used This Remote-Controlled Robot to Extinguish the Notre Dame Blaze. In IEEE Spectrum: Technology, Engineering, and Science News; IEEE: Piscataway, NJ, USA, 2019.

4. Raghavendran, P.S.; Suresh, M.; Ranjith Kumar, R.; Ashok Kumar, R.; Mahendran, K.; Swathi, S.; Kamesh, L.; Sanjay, R. An Intelligent Remote-Controlled Fire Fighting Machine for Autonomous Protection of Human being. Int. J. Adv. Res. Sci. Eng. Technol. 2018, 5, 7620-7626.

5. Nikitin, V.; Golubin, S.; Belov, R.; Gusev, V.; Andrianov, N. Development of a robotic vehicle complex for wildfire-fighting by means of fire-protection roll screens. In IOP Conference Series: Earth and Environmental Science; IOP Conference Series; Earth and Environmental Science: Bristol, UK, 2019; Volume 226, p. 012003.

6. Steopan, M.; Schonstein, C.; Bogdan, A.V. Mobile Robotic Platform for Firefighting-Concept Development, Finissing and Mockup Buildup. J. Acta Tech. Napoc. Ser. Appl. Math. Mech. Eng. 2020, 63, 269-274.

7. Kurvinen, K.; Smolander, P.; Pöllänen, R.; Kuukankorpi, S.; Kettunen, M.; Lyytinen, J. Design of a Radiation Surveillance Unit for an Unmanned Aerial Vehicle. J. Environ. Radioact. 2005, 81, 1-10. [CrossRef]

8. Yukihisa, S.; Takeshi, S.; Yukiyasu, N.; Atsuya, K.; Tatsuo, T. The Aerial Radiation Monitoring in Japan after the Fukushima Daiichi Nuclear Power Plant Accident. Prog. Nucl. Sci. Technol. 2014, 4, 76-80.

9. Lowdon, M.; Martin, P.G.; Hubbard, M.; Taggart, M.; Connor, D.T.; Verbelen, Y.; Sellin, P.; Scott, T.B. Evaluation of Scintillator Detection Materials for Application within Airborne Environmental Radiation Monitoring. Sensors 2019, 19, 3828. [CrossRef] [PubMed]

10. Zhang, K.; Hutson, C.; Knighton, J.; Hermann, G.; Scott, T. Radiation Tolerance Testing Methodology of Robotic Manipulator Prior to Nuclear Waste Handling. Front. Robot. AI 2020, 7, 10. [CrossRef]

11. Wang, W.; Gao, W.; Zhao, S.; Cao, W.; Du, Z. Robot Protection in the Hazardous Environments: Chapter 4; InTechOpen: London, UK, 2017.

12. Oh, Y.T. Study of Mechanical Characteristics and Thermal Barrier Coating on Firefighting Robot. Int. J. Mech. Mechatron. Eng. Ijmme-Ijens 2018, 18, 83-88.

13. AlHaza, T.; Alsadoon, A.; Alhusinan, Z.; Jarwali, M.; Alsaif, K. New Concept for Indoor Fire Fighting Robot. Procedia Soc. Behav. Sci. 2015, 195, 2343-2352. [CrossRef]

14. Zhu, J.; Pan, L.; Zhao, G. An Improved Near-Field Computer Vision for Jet Trajectory Falling Position Prediction of Intelligent Fire Robot. Sensors 2020, 20, 7029. [CrossRef] 
15. Anderson, J.; Lee, D.J.; Schoenberger, R.; Wei, Z.; Archibald, Z.K. Semi-Autonomous Unmanned Ground Vehicle Control System. In Unmanned Systems Technology VIII; Defense and Security Symposium: Orlando, FL, USA, 2006.

16. Grigore, L.Ș.; Priescu, I.; Joița, D.; Holban-Oncioiu, I. The Integration of Collaborative Robot Systems and Their Environmental Impacts. Process 2020, 8, 494. [CrossRef]

17. McNamee, M.; Marlair, G.; Truchot, B.; Meacham, B. Research Roadmap: Environmental Impact of Fires in the Built Environment-Final Report; NFPA-National Fire Protection Association: Quincy, MA, USA, 2020.

18. Akhlouf, M.A.; Castro, N.A.; Couturier, A. Unmanned Aerial Systems for Wildland and Forest Fires: Sensing, Perception, Cooperation and Assistance. arXiv 2020, arXiv:200413883.

19. Cruz, H.; Eckert, M.; Meneses, J.; Martínez, J.-F. Efficient Forest Fire Detection Index for Application in Unmanned Aerial Systems (UASs). Sensors 2016, 16, 893. [CrossRef] [PubMed]

20. Sousa, M.J.; Moutinho, A.; Almeida, M. Thermal Infrared Sensing for Near Real-Time Data-Driven Fire Detection and Monitoring Systems. Sensors 2020, 20, 6803. [CrossRef]

21. Viedma, O.; Almeida, D.R.A.; Moreno, J.M. Postfire Tree Structure from High-Resolution LiDAR and RBR Sentinel 2A Fire Severity Metrics in a Pinus halepensis-Dominated Burned Stand. Remote Sens. 2020, 12, 3554. [CrossRef]

22. Kwet, C.; Lam, Y.; Man, L.; Koonjul, Y.; Nagowah, L. A low cost autonomous unmanned ground vehicle. Future Comput. Inform. J. 2018, 3, 304-320.

23. Tamura, Y.; Amano, H.; Ota, J. Analysis of Firefighting Skill with a teleoperated robot. Robomech J. 2020, 7, 14. [CrossRef]

24. Muppidi, S. Development of a Low-Cost Controller and Navigation System for Unmanned Ground Vehicle. Bachelor's Thesis, University of Ontario Institute of Technology, Oshawa, ON, Canada, 2008.

25. Patle, B.K.; Ganesh-Babu, L.; Pandey, A.; Parhi, D.R.K.; Jagadeesh, A. A review: On path strategies for navigation of mobile robot. Def. Technol. 2019, 15, 582-606. [CrossRef]

26. Berns, K.; Nezhadfard, A.; Tosa, M.; Balta, H.; De Cubber, G. Unmanned Ground Robots for Rescue Tasks: Chapter 4; InTechOpen: London, UK, 2017.

27. Oh, S.B.; Chung, Y.H. Smart and Safe Vehicle Monitoring with Fuzzy Integral and Haar-like Features. Int. J. Comput. Commun. Control 2013, 8, 588-593. [CrossRef]

28. Väljaots, E.; Sell, R.; Kaeeli, M. Motion and Energy Efficiency Parameters of Unmanned Ground Vehicle. Period. Solid State Phenom. 2015, 220, 934-939. [CrossRef]

29. Grant, C.; Hamins, A.; Bryner, N.; Jones, A.; Koepke, G. Research Roadmap for Smart Fire Fighting; Summary Report; NIST-National Institute of Standards and Technology: Gaithersburg, MD, USA, 2015.

30. Han, Y.; Luan, W.; Jiang, Y.; Zhang, X. Protection of electronic Devices on nuclear Rescue robot: Passive thermal control. J. Appl. Therm. Eng. 2016, 101, 224-230. [CrossRef]

31. Sevinchan, E. Investigation of Thermal Management Options for Robots. Master's Thesis, University of Ontario Institute of Technology, Oshawa, ON, Canada, 2018.

32. Ciupitu, L. Adaptive Balancing of Robots and Mechatronic Systems. Robotics 2018, 7, 12. [CrossRef]

33. Kulich, M.; Kubalík, J.; Přeučil, L. An Integrated Approach to Goal Selection in Mobile Robot Exploration. Sensors 2019, 19, 1400. [CrossRef]

34. Garzón, M.; Valente, J.; Zapata, D.; Barrientos, A. An Aerial-Ground Robotic System for Navigation and Obstacle Mapping in Large Outdoor Areas. Sensors 2013, 13, 1247-1267. [CrossRef]

35. Szrek, J.; Zimroz, R.; Wodecki, J.; Michalak, A.; Góralczyk, M.; Worsa-Kozak, M. Application of the Infrared Thermography and Unmanned Ground Vehicle for Rescue Action Support in Underground Mine-The AMICOS Project. Remote Sens. 2021, 13, 69. [CrossRef]

36. Ștefan, A.; Ștefan, A.; Constantin, D.; Mateescu, C.; Cartal, L.A. Aspects of kinematics and dynamics for Payload UAVs. In Proceedings of the 7th International Conference on Electronics, Computers and Artificial Intelligence (ECAI), Bucharest, Romania, 25-27 June 2015; pp. WF1-WF4.

37. Martínez, J.L.; Morales, J.; Sánchez, M.; Morán, M.; Reina, A.J.; Fernández-Lozano, J.J. Reactive Navigation on Natural Environments by Continuous Classification of Ground Traversability. Sensors 2020, 20, 6423. [CrossRef]

38. Wong, J.Y. Terramechanics and Off-Road Vehicle Engineering: Terrain Behaviour, Off-Road Vehicle Performance and Design, 2nd ed.; Butterworth Heinemann: Oxford, UK, 2009; p. 488, ISBN 978-0-75-068561-0, e-ISBN 978-0-08-094253-7.

39. Ciobotaru, T. Semi-Empiric Algorithm for Assessment of the Vehicle Mobility. Leonardo Electron. J. Pract. Technol. 2009, 8, 19-30.

40. Yu, W.; Chuy, O., Jr.; Collins, E.G., Jr.; Hollis, P. Dynamic Modeling of a Skid-Steered Wheeled Vehicle with Experimental Verification. In Proceedings of the 2009 IEEE/RSJ International Conference on Intelligent Robots and Systems, St. Louis, MO, USA, 11-15 October 2009.

41. Alexa, O.; Coropețchi, I.; Vasile, A.; Oncioiu, I.; Grigore, L.Ș. Considerations for Determining the Coefficient of Inertia Masses for a Tracked Vehicle. Sensors 2020, 20, 5587. [CrossRef]

42. Wong, J.Y.; Chiang, C.F. A general theory for skid steering of tracked vehicles. Proc. Inst. Mech. Eng. Part D J. Automob. Eng. 2001, 215, 343-355. [CrossRef]

43. Cojocaru-Greblea, T.; Bontos, D.; Vasiliu, N.; Dobre, A. Redundant Steering Systems for Articulated Vehicles. In Proceedings of the 17th International Multidisciplinary Scientific GeoConference SGEM 2017, Sofia, Bulgaria, 27 June-6 July 2017. 
44. Trucchia, A.; D’Andrea, M.; Baghino, F.; Fiorucci, P.; Ferraris, L.; Negro, D.; Gollini, A.; Severino, M. PROPAGATOR: An Operational Cellular-Automata Based Wildfire Simulator. Fire 2020, 3, 26. [CrossRef]

45. Ott, C.W.; Adhikari, B.; Alexander, S.P.; Hodza, P.; Xu, C.; Minckley, T.A. Predicting Fire Propagation across Heterogeneous Landscapes Using WyoFire: A Monte Carlo-Driven Wildfire Model. Fire 2020, 3, 71. [CrossRef]

46. Cicione, A.; Gibson, L.; Wade, C.; Spearpoint, M.; Walls, R.; Rush, D. Towards the Development of a Probabilistic Approach to Informal Settlement Fire Spread Using Ignition Modelling and Spatial Metrics. Fire 2020, 3, 67. [CrossRef]

47. Wallace, L.; Hally, B.; Hillman, S.; Jones, S.D.; Reinke, K. Terrestrial Image-Based Point Clouds for Mapping Near-Ground Vegetation Structure: Potential and Limitations. Fire 2020, 3, 59. [CrossRef]

48. Zhang, J.J.; Ye, Z.Y.; Li, K.F. Multi-sensor information fusion detection system for fire through back propagation neural network. PLOS ONE 2020, 15, 13. [CrossRef]

49. Kim, J.H. Autonomous Navigation, Perception and Probabilistic Fire Location for an Intelligent Firefighting Robot. Ph.D. Thesis, Mechanical Engineering to the Faculty Virginia Polytechnic Institute Blacksburg, Blacksburg, VA, USA, 2014.

50. Castro Jiménez, L.E.; Edgar, A. Martínez-García, E.A. Thermal Image Sensing Model for Robotic Planning and Search. Sensors 2016, 16, 1253. [CrossRef]

51. Le, Q.X.; Dao, V.T.N.; Torero, J.L.; Maluk, C.; Bisby, L. Effects of temperature and temperature gradient on concrete performance at elevated temperatures. Adv. Struct. Eng. 2018, 21, 1223-1233. [CrossRef]

52. Agarwal, A.; Choe, L.; Varma, A.H. Fire Design of Steel Columns: Effects of Thermal Gradients. J. Constr. Steel Res. 2014, 93, 107-118. [CrossRef]

53. Gao, J.; Ye, W.; Guo, J.; Li, Z. Deep Reinforcement Learning for Indoor Mobile Robot Path Planning. Sensors 2020, $20,5493$. [CrossRef] [PubMed]

54. IMOA-International Molybdenum Association. Stainless Steel Fire Performance \& Radiant Heat Transfer. Available online: https:/ / www.imoa.info/molybdenum-uses/molybdenum-grade-stainless-steels/architecture/fire-resistance.php (accessed on 13 January 2021).

55. Silva, L.S.; Santiago, A. Behaviour of steel joints under fire loading. J. Steel Compos. Struct. 2005, 5, 485-513. [CrossRef]

56. Zak, C.; Urban, J.; Tran, V.; Fernandez-Pello, C. Flaming Ignition Behavior of Hot Steel and Aluminum Spheres Landing in Cellulose Fuel Beds. Fire Saf. Sci. 2014, 11, 1368-1378. [CrossRef]

57. Brucker, K.A.; Majdalani, J. Effective thermal conductivity of common geometric shapes. Int. J. Heat Mass Transf. 2005, 48, 4779-4796. [CrossRef]

58. Ryzhenkov, A.V.; Pogorelov, S.I.; Loginova, N.A.; Mednikov, A.F.; Tkhabisimov, A.B. Radiant heat transfer reduction methods in heat insulation of power equipment. Wit Trans. Eng. Sci. 2016, 106, 107-114.

59. Tahmasbi, V.; Noori, S. Thermal Analysis of Honeycomb Sandwich Panels as Substrate of Ablative Heat Shield. J. Thermophys. Heat Transf. 2017, 32, 1-12. [CrossRef]

60. Kantor, R. Modelling of a coupled radiation-conduction heat transfer through a heat shield in vacuum thermal isolation applications, IX International Conference on Computational Heat and Mass Transfer. Procedia Eng. 2016, 157, 271-278. [CrossRef]

61. SMOOTH—Smart Robots for Fighting. Available online: https:/ / ec.europa.eu/research/participants/documents/downloadPublic? documentIds=080166e5bb6ea8f9\&appId=PPGMS (accessed on 14 January 2021).

62. Lundberg, C. Assessment and Evaluation of Man-portable Robots for High-risk Professions in Urban Settings. Perform. Metr. Intell. Syst. 2007, 76-83. [CrossRef]

63. Supacat All Terrain Mobility Platform (ATMP) and Springer. Available online: https://thinkdefence.wordpress.com/supacatterrain-mobility-platform-atmp/ (accessed on 14 January 2021).

64. Li, S.; Feng, C.; Niu, Y.; Shi, L.; Wu, Z.; Song, H. A Fire Reconnaissance Robot Based on SLAM Position, Thermal Imaging Technologies, and AR Display. Sensors 2019, 19, 5036. [CrossRef] [PubMed]

65. Tan, C.F.; Liew, S.M.; Alkahari, M.R.; Ranjit, S.S.S.; Said, M.R.; Chen, W.; Rauterberg, G.W.M.; Sivakumar, D. Fire Fighting Mobile Robot: State of the Art and Recent Developmen. Aust. J. Basic Appl. Sci. 2013, 7, 220-230.

66. Liu, P.; Yu, H.; Cang, S.; Vladareanu, L. Robot-Assisted Smart Firefighting and Interdisciplinary Perspectives. In Proceedings of the 22nd International Conference on Automation and Computing (ICAC), Colchester, UK, 7-8 September 2016 ; pp. 395-401.

67. Grigore, L.S.; Priescu, I.; Grecu, D.L. Applied Artificial Intelligence in Fixed and Mobile Robotic Systems, Cap 4 Terrestrial Mobile Robots; AGIR (General Association of Engineers from Romania): Bucharest, Romania, 2020; p. 703. ISBN 978-973-72-0767-8.

68. Silk, E. Radiative Heat Transfer Analysis. In Introduction to Spacecraft Thermal Design; Cambridge Aerospace Series; Cambridge University Press: Cambridge, UK, 2020; pp. 64-113. [CrossRef] 